\title{
Malignant transformation of abdominal wall endometriosis to clear cell carcinoma: case report
}

\author{
João Kleber de Almeida Gentile', Renato Migliore', Fábio Jorge Neubaner Kistenmacker', Marcio Menezes de Oliveira" \\ Rodrigo Biscuola Garcial', Fang Chia Bin"v, Pedro Marcos Santinho Bueno de Souza'", José César Assef"
}

Hospital do Servidor Público Municipal (HSPM-SP), São Paulo (SP), Brazil

'MD. Resident Physician, Department of Digestive Surgery, Hospital do Servidor Público Municipal (HSPM-SP), São Paulo (SP), Brazil. (D)orcid.org/0000-0001-8650-2703

"MD. Resident of General Surgery, Department of General Surgery, Hospital do Servidor Público Municipal (HSPM), São Paulo (SP), Brazil.

"'MD. Attending Physician, Department of Digestive Surgery, Hospital do Servidor Público Municipal (HSPM-SP), São Paulo (SP), Brazil.

"MD. Department of Digestive System Surgery, Hospital do Servidor Público Municipal (HSPM-SP), São Paulo (SP), Brazil.

\section{KEY WORDS:}

Endometriosis.

Abdominal wall.

Cell transformation, neoplastic.

Adenocarcinoma, clear cell.

\begin{abstract}
BACKGROUND: Malignant transformation of endometriosis in the abdominal wall is a rare and still poorly understood event. Less than 30 cases have been reported in the worldwide literature. Most cases of solid tumors are report in a previous abdominal scar with malignant transformation of a focus of endometriosis. Presence of lymph node metastases in nearby chains is frequent and is associated with poor prognosis.

CASE REPORT: We report a case of a 42-year-old woman with a history of abdominal surgery (Pfannenstiel) to resect abdominal wall endometriosis. Physical examination revealed a solid mass of approximately $10 \mathrm{~cm} \times 6 \mathrm{~cm}$ in the anterior wall of the abdomen. Computed tomography (CT) of the abdomen and pelvis showed a heterogeneous, predominantly hypoattenuating expansive formation measuring $10.6 \mathrm{~cm} x$ $4.7 \mathrm{~cm} \times 8.3 \mathrm{~cm}$. The patient underwent exploratory incisional laparotomy, block resection of the abdominal mass and lymphadenectomy of the external and inguinal iliac chains. The abdominal wall was reconstructed using a semi-absorbable tissue-separating screen to reconstitute the defect caused by resection of the tumor. Histological evaluation revealed infiltration by malignant epithelioid neoplasia, thus confirming the immunohistochemical profile of adenocarcinoma with clear cell components. Lymphadenectomy showed metastatic involvement of an external iliac chain lymph node.

CONCLUSION: Resection of the mass along with the abdominal wall, with wall margins, is the most effective treatment. Reconstruction is a challenge for surgeons. The patient has been followed up postoperatively for eight months, without any evidence of disease to date.
\end{abstract}

\section{INTRODUCTION}

Endometriosis is defined as the presence of stroma and endometrial glands outside the uterine cavity. It affects approximately $15-40 \%$ of women of childbearing age. The most common site is the abdominal cavity, specifically in the pelvis and occasionally at extra-pelvic sites. ${ }^{1,2}$ Abdominal wall endometriosis accounts for $0.4-2 \%$ of the cases, and is mostly found in the umbilical scar and in the scar of previous abdominal incisions, especially in cesarean scars, laparoscopies and appendectomies. ${ }^{2}$

In patients with abdominal wall endometrioma, the mean time taken to reach the diagnosis is 6 to 20 years after the initial surgery, and $14.3-26 \%$ of the cases show an association with pelvic endometriosis. ${ }^{2}$ The endometrioma is diagnosed preoperatively only in $20-50 \%$ of the cases, and the typical complaint is most frequently cyclical menstrual pain. The differential diagnoses for an abdominal mass associated with a previous surgical incision in the abdominal wall include abscess, hematoma, hernia, desmoid tumors, sarcomas and metastatic disease. ${ }^{1}$

Malignant transformation of an abdominal wall endometrioma is an extremely rare event. Extensive local excision with surgical margins seems to be the only effective treatment, and it is almost always necessary to correct the defect of the abdominal wall with prosthetic surgical or cutaneous flaps for the closure of the abdominal wall.

Here we report a case of abdominal wall endometrioma that evolved into clear cell carcinoma of the abdominal wall with metastases to the lymphatic system. 


\section{CASE REPORT}

The patient was a 42 -year-old female, with one previous pregnancy, with a history of cesarean section seven years previously and resection of endometriosis of the cephalic scar (Pfannenstiel) two years previously at another service, for which a histopathological diagnosis of abdominal wall endometriosis was made.

Her condition evolved with progressive expansion in the region previously resected, for eight months, leading to presence of a bulging mass in the right side of the anterior abdominal wall, with cyclical local pain. During the investigation period, the patient said that she did not have any genitourinary or gastrointestinal symptoms, or any presence of lymph nodes or systemic symptoms.

Physical examination revealed a solid mass of approximately $10 \mathrm{~cm} \times 6 \mathrm{~cm}$ in the anterior wall of the abdomen bordering the pubis. It extended inferiorly to the umbilical scar and laterally to the upper border of the iliac crest. At the time of the physical examination, there was no lymph node swelling in the inguinal region.

Laboratory tests and tumor marker investigations (CA 125, CA 19-9, CEA and alpha-fetoprotein) were requested and these were found to be within normal limits. Computed tomography (CT) of the abdomen and pelvis revealed a heterogeneous expansive formation that was predominantly hypoattenuating, with images suggestive of internal septation. It measured around $10.6 \mathrm{~cm} \mathrm{x}$ $4.7 \mathrm{~cm} \mathrm{x} 8.3 \mathrm{~cm}$ along the major transverse, anteroposterior and longitudinal axes, respectively, and was located in the anterior pelvic wall, with the largest axis to the right of the midline, involving the rectus abdominis muscle (Figure 1).

The patient underwent exploratory laparotomy by means of a Pfannenstiel incision, followed by block resection of the abdominal mass (Figure 2) with margins to the peritoneum, along with lymphadenectomy of the external and inguinal iliac chains. The abdominal wall was reconstructed to reconstitute the defect caused

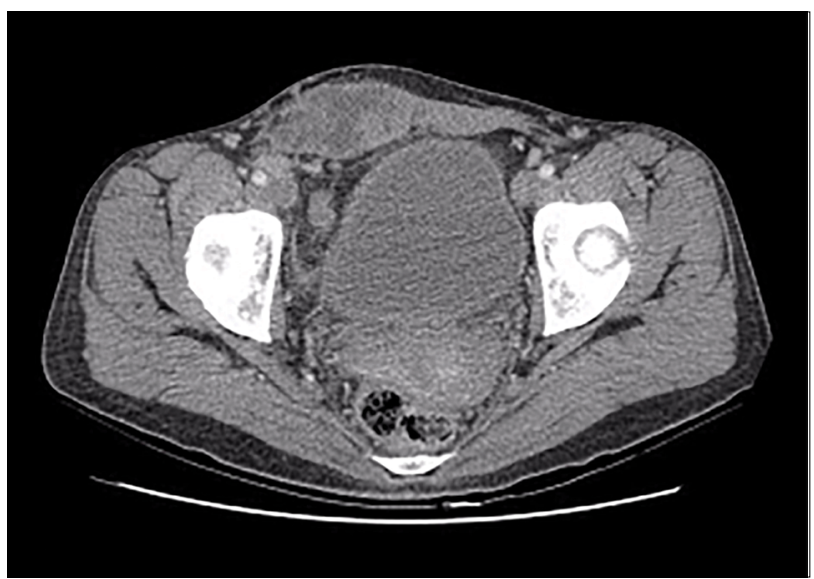

Figure 1. Computed tomography scan of the abdomen and pelvis (portal phase) showing an expansive process in the anterior abdominal wall and pelvis and lymph node enlargement in the external and inguinal iliac chains. by resection of the tumor, using a semi-absorbable tissue-separating screen composed of a polypropylene parietal face and a visceral face coated with carboxymethyl cellulose. This rectangular sodium hyaluronate mesh measured $20.3 \mathrm{~cm}$ x $30.5 \mathrm{~cm}$ (Sempramesh IP Composite Bard Davol Inc.).

Histological analysis on the abdominal mass revealed infiltration by malignant epithelioid neoplasia into soft tissues, thus confirming the immunohistochemical profile of adenocarcinoma with clear cell components (Figure 3). The antigens investigated in the immunohistochemical evaluation are listed in Table 1. Lymphadenectomy showed metastatic involvement of an external iliac chain lymph node (1/8), and that other

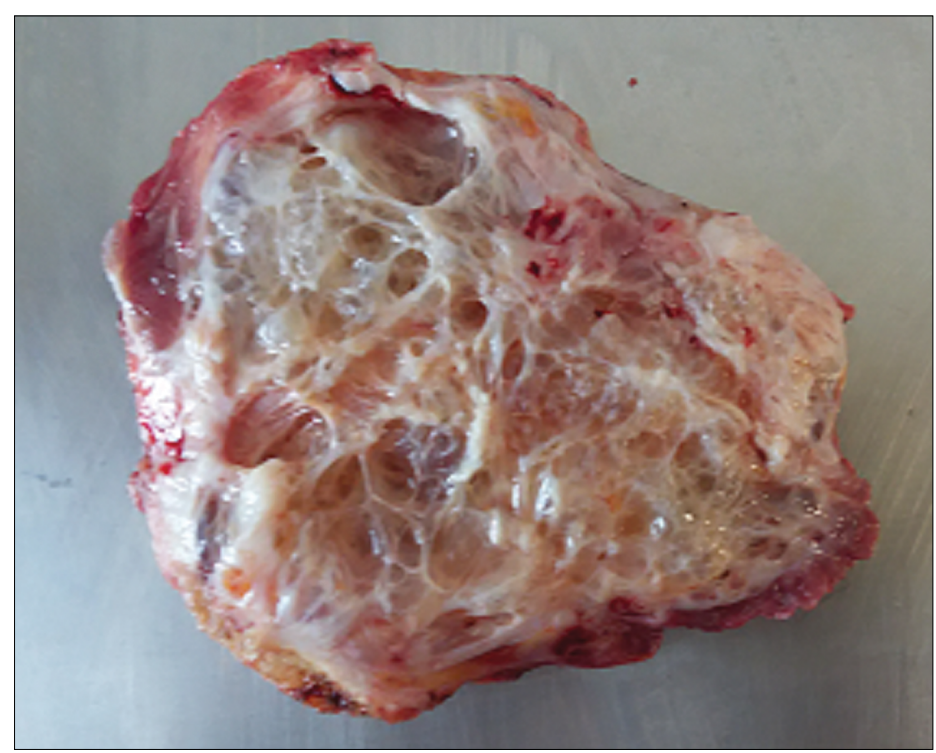

Figure 2. Macroscopic appearance demonstrating areas of cystic and trabecular components.

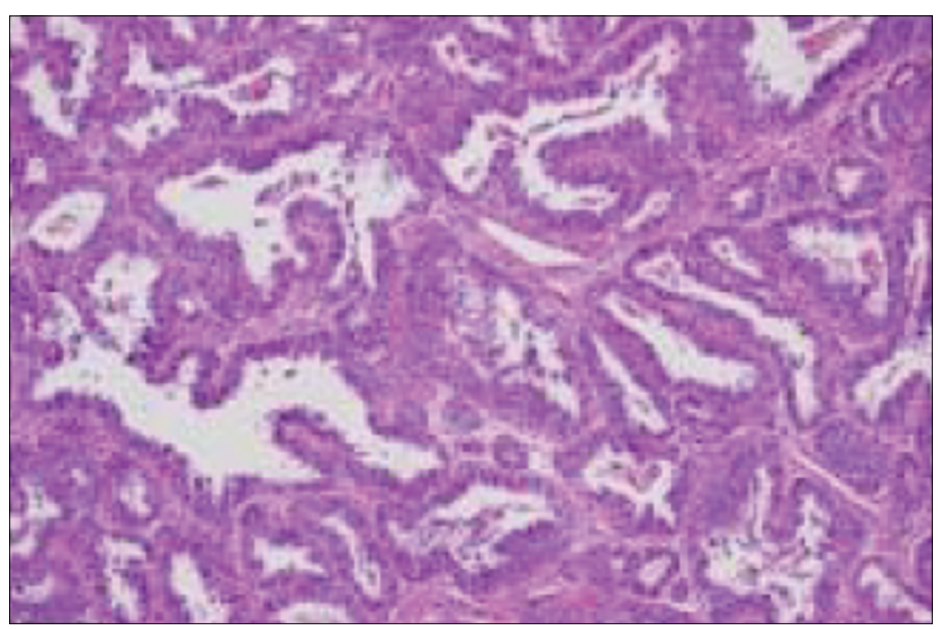

Figure 3. Histological section of clear cell endometrioid adenocarcinoma demonstrating loss of glandular architecture and stroma (hematoxylin and eosin; $x$ 400). 
lymph nodes of the iliac and inguinal chains presented lymphoid hyperplasia $(0 / 11)$.

Our patient is in her second postoperative month, without having presented any clinical or surgical intercurrence to date. She is being followed up by the oncology sector and an adjuvant chemotherapy scheme has been indicated.

\section{DISCUSSION}

Malignant transformation of endometriosis is quite rare and affects less than $1 \%$ of the female population suffering from this condition. In the literature, the most common site of malignant transformation of endometriosis foci is the ovaries, while $20 \%$ of the cases occur at extragonadal sites, including the rectovaginal septum, colon and distal organs such as the abdominal wall. Less than $5 \%$ of these cases are carcinomas of clear cell origin like the case reported here. ${ }^{3}$

This malignant transformation in the abdominal wall is an extremely rare event, with less than 30 case reports in the worldwide literature. These cases consisted of endometrioid carcinoma (70\%), sarcoma (25\%) and clear cell carcinoma (5\%). ${ }^{4}$

Sampson was one of the first authors to report a case of malignancy of an endometriosis outbreak. He proposed three criteria for diagnosing malignant transformation of endometriosis:

1. Demonstration of neoplastic and benign endometrial tissue in the tumor;

2. Histological type compatible with endometrial origin;

3. No other primary site identified. ${ }^{5}$

In 1953, Scott added a fourth criterion: histological presence of benign endometriosis and carcinoma with glandular transformation

Table 1. Immunohistochemical profile and antigens investigated

\begin{tabular}{lc} 
Antigen & Result \\
D AE1/AE3 & Positive \\
CD 34 & Negative \\
CK 7 & Positive \\
CK 20 & Negative \\
Estrogen receptor & Negative \\
WT-1 & Negative \\
Vimentin & Negative \\
\hline
\end{tabular}

with atypias. Few reported cases have met all four proposed criteria, and the etiogenesis of such cases remains unknown. ${ }^{6}$

Malignancy of a focus of endometriosis on a previous scar on the abdominal wall is very rare, with a reported prevalence of $0.03 \%$. It can affect all layers of the abdominal wall and the growth of such masses is exponential, reaching diameters greater than $10 \mathrm{~cm} .^{7}$

In our case, the mass appeared in the anterior wall of the abdomen without evidence of abdominal cavity involvement from abdominal CT. The abdominal wall itself was limited by the peritoneum. Our patient underwent preoperative screening for a primary focus of neoplasia, by means of upper gastrointestinal endoscopy, colonoscopy and thyroid ultrasonography. All of these were negative for neoplasms.

We reviewed the literature through MEDLINE, PubMed, Embase and LILACS using the English keywords "endometriosis", "cell transformation", "adenocarcinoma" and "abdominal wall". We found only 17 reports, as shown in Table 2 , and 15 reports had clinical presentation similar to the reported case. Table $3^{7-21}$ lists the reports in the literature describing the different types of treatment for clear cell carcinomas of the abdominal wall that were derived from an endometrioid focus on a previous abdominal scar. Local invasion is an important biological feature for transformation of endometriosis into invasive carcinoma. On the other hand, although lymphatic dissemination may be present, it has only been reported in three cases. ${ }^{7-9}$

At the time of the pre-surgical evaluation, it was difficult to make a diagnosis of lymph node involvement. However, the presence of lymph node enlargement in the inguinal region and in the external iliac chain was observed on CT scans. This was investigated using computerized tomography with 18-fluorodeoxyglucose positron emission tomography (FDG-PET).

Presence of a compromised lymph node in the $2-\mathrm{cm}$ external iliac chain was demonstrated, with standardized uptake values (SUV) for the abdominal mass of 4.16 and 2.51 in the iliac lymph node. There were no other signs of FDG uptake.

In our case, lymphadenectomy of the external and inguinal iliac chain was performed, and the metastatic involvement of the lymph node caused by carcinoma was confirmed through histological analysis.

Table 2. Search of the literature in medical databases for cases of degeneration of abdominal wall endometriosis for clear cell carcinoma. (Search was conducted on April 14, 2017)

\begin{tabular}{|c|c|c|c|}
\hline Database & Search strategies & Papers found & $\begin{array}{l}\text { Reports of cases with } \\
\text { lymphatic dissemination }\end{array}$ \\
\hline MEDLINE (via PubMed) & $\begin{array}{l}\text { endometriosis and cell transformation and adenocarcinoma and } \\
\text { abdominal wall "case reports" [publication type] }\end{array}$ & 17 & 2 \\
\hline Embase (via Elsevier) & $\begin{array}{l}\text { endometriosis and cell transformation and adenocarcinoma and } \\
\text { abdominal wall "case reports" [publication type] }\end{array}$ & 0 & 0 \\
\hline LILACS (via Bireme) & $\begin{array}{l}\text { endometriosis and cell transformation and adenocarcinoma and } \\
\qquad \text { abdominal wall }\end{array}$ & 16 & 1 \\
\hline
\end{tabular}


Table 3. Reported cases of clear cell carcinoma of the abdominal wall derived from focus of endometriosis

\begin{tabular}{|c|c|c|c|}
\hline Author & Treatment & Follow-up (months) & Outcome \\
\hline Schineber and Wagner-Kolb8 (a) & HTA + SOB, R-Ad, Progesterone & 18 & Death \\
\hline Hitti et al..$^{9}(a)$ & Resection, $\mathrm{HTA}+\mathrm{SOB}$ & 30 & Alive without evidence of disease \\
\hline Miller et al. ${ }^{10}(\mathrm{a})$ & Resection, HTA + SOB, R-Ad, Q-Ad & 60 & Alive without evidence of disease \\
\hline Ishida et al. ${ }^{12}(a)$ & Resection, R-Ad & 48 & Death \\
\hline Sergent et al. ${ }^{13}(a)$ & $\mathrm{HTA}+\mathrm{SOB}, \mathrm{Q}-\mathrm{Ad}$ & 9 & Death \\
\hline Bats et al. ${ }^{7}$ (a) & Q-Neo, Resection, HTA + SOB & NA & Not reported \\
\hline Razzouk et al. ${ }^{16}(b)$ & Resection, Q-Ad & 6 & Death \\
\hline Williams et al. ${ }^{17}(\mathrm{a})$ & Resection, HTA + SOB, Q-Ad & 11 & Death \\
\hline Yan et al. ${ }^{18}$ & Resection, Q-Ad & 24 & Alive without evidence of disease \\
\hline Mert et al. ${ }^{19}(a)$ & Resection, HTA + SOB, R-Ad & 31 & Alive without evidence of disease \\
\hline
\end{tabular}

$\mathrm{TAH}=$ total abdominal hysterectomy; $\mathrm{BSO}=$ bilateral salpingo-oophorectomy; $\mathrm{R}=$ radiotherapy; $\mathrm{Q}=$ chemotherapy; $\mathrm{Ad}=$ adjuvant; $\mathrm{Neo}=$ neoadjuvant; a: clear cell serous carcinoma; b: clear cell and endometrioid carcinoma

Radical resection is considered to be the primary treatment for endometrioid carcinoma of the wall. Carboplatin-based chemotherapy and radiation therapy schemes have been proposed without any evidence of improved prognosis or survival. ${ }^{7}$

Due to the rarity of this tumor, the long-term survival following treatment is unknown. However, some recent reports have shown that aggressive radical surgery with total tumor excision with free margins, together with lymphadenectomy of the inguinal and iliac chains may be beneficial for these patients' disease-free survival.

\section{CONCLUSION}

Malignant transformation to clear cell carcinoma from a focus of endometriosis on the abdominal wall is a rare and poorly understood complication. Most recent studies have shown that aggressive surgical resection with safety margins associated with lymphadenectomy is still the most effective treatment with the highest survival rates. The role of adjuvant therapy remains unclear and therefore further studies to assess the long-term benefits are required.

In our case, lymphadenectomy of the external and inguinal iliac chain was performed, and the metastatic involvement of the lymph node caused by carcinoma was confirmed through histological analysis.

\section{REFERENCES}

1. Blanco RG, Parithivel VS, Shah AK, et al. Abdominal wall endometriomas. Am J Surg. 2003;185(6):596-8.

2. Zhao X, Lang J, Leng J, et al. Abdominal wall endometriomas. Int J Gynaecol Obstet. 2005;90(3):218-22.
3. Omranipour R, Najafi M. Papillary serous carcinoma arising in abdominal wall endometriosis treated with neoadjuvant chemotherapy and surgery. Fertil Steril. 2010;93(4):1347.e17-8.

4. Shalin SC, Haws AL, Carter DG, Zarrin-Khameh N. Clear cell adenocarcinoma arising from endometriosis in abdominal wall cesarean section scar: a case report and review of the literature. J Cutan Pathol. 2012;39(11):1035-41.

5. Sampson JA. Endometrial carcinoma of the ovary arising in endometrial tissue in that organ. American Journal of Obstetrics \& Gynecology. 1925;9(1):111-4. Available from: http://www.ajog.org/article/S00029378(25)90949-0/abstract. Accessed in 2017 (Jul 14).

6. Scott RB. Malignant changes in endometriosis. Obstet Gynecol. 1953;2(3):283-9.

7. Bats AS, Zafrani Y, Pautier P, Duvillard P, Morice P. Malignant transformation of abdominal wall endometriosis to clear cell carcinoma: case report and review of the literature. Fertil Steril. 2008;90(4):1197.e13-6.

8. Schineber D, Wagner-Kolb D. [Malignant transformation of extragenital endometriosis]. Geburtshilfe Frauenheilkd. 1986;46(9):658-9.

9. Hitti IF, Glasbergg SS, Lubicz S. Clear cell carcinoma arising in extraovarian endometriosis: report of three cases and review of the literature. Gynecol Oncol. 1990;39(3):314-20.

10. Miller DM, Schouls JJ, Ehlen TG. Clear cell carcinoma arising in extragonadal endometriosis in a caesarean section scar during pregnancy. Gynecol Oncol. 1998;70(1):127-30.

11. Park SW, Hong SM, Wu HG, Ha SW. Clear cell carcinoma arising in a Cesarean section scar endometriosis: a case report. J Korean Med Sci. 1999;14(2):217-9.

12. Ishida GM, Motoyama T, Watanabe T, Emura I. Clear cell carcinoma arising in a cesarean section scar. Report of a case with fine needle aspiration cytology. Acta Cytol. 2003;47(6):1095-8. 
13. Sergent F, Baron M, Le Cornec JB, et al. Malignant transformation of abdominal wall endometriosis: a new case report]. J Gynecol Obstet Biol Reprod (Paris). 2006;35(2):186-90.

14. Alberto VO, Lynch M, Labbei FN, Jeffers M. Primary abdominal wall clear cell carcinoma arising in a Caesarean section scar endometriosis. Ir J Med Sci. 2006;175(1):69-71.

15. Rust MM, Susa J, Naylor R, Cavuoti D. Clear cell carcinoma in a background of endometriosis. Case report of a finding in a midline abdominal scar 5 years after a total abdominal hysterectomy. Acta Cytol. 2008;52(4):475-80.

16. Razzouk K, Roman H, Chanavaz-Lacheray l, et al. Mixed clear cell and endometrioid carcinoma arising in parietal endometriosis. Gynecol Obstet Invest. 2007;63(3):140-2.

17. Williams C, Petignat P, Belisle A, Drouin P. Primary abdominal wall clear cell carcinoma: case report and review of literature. Anticancer Res. 2009;29(5):1591-3.

18. Yan Y, Li L, Guo J, Zheng Y, Liu Q. Malignant transformation of an endometriotic lesion derived from an abdominal wall scar. Int J Gynaecol Obstet. 2011;115(2):202-3.

19. Mert I, Semaan A, Kim S, Ali-Fehmi R, Morris RT. Clear cell carcinoma arising in the abdominal wall: two case reports and literature review. Am J Obstet Gynecol. 2012;207(2):e7-9.

20. Markopoulos C, Gogas H, Eleftheriou G, Floros D. Endometrioid carcinoma arising in a scar of caesarean section. Case report. Eur J Gynaecol Oncol. 1996;17(6):520-1.

21. Gücer F, Reich O, Kömetter R, Pieber D. Endometroid carcinoma arising with a scar endometriosis. Eur J Gynaecol Oncol. 1997;18(1):42-3.

\section{Conflict of interest: None}

Sources of funding: None

Date of first submission: April 9, 2017

Last received: April 22, 2017

Accepted: April 30, 2017

\section{Address for correspondence:}

João Kleber de Almeida Gentile

Seção de Técnica de Cirurgia Digestiva, Hospital do Servidor Público

Municipal (HSPM-SP)

Rua Castro Alves, 60

São Paulo (SP) — Brasil

CEP 01532-000

Tel. (+55 11) 3726-8591

E-mail: joaokleberg@gmail.com 